\title{
A copper pyramidal fractal antenna fabricated with green-laser powder bed fusion
}

\author{
Kerry Johnson ${ }^{1}$ (D) Edward Burden ${ }^{2} \cdot$ Michael Shaffer $^{3} \cdot$ Tobias Noack $^{3} \cdot$ Matthias Mueller $^{3} \cdot$ Jason Walker $^{1}$. \\ Eric MacDonald ${ }^{4} \cdot$ Pedro Cortes $^{1} \cdot$ Joel Quintana $^{4}$
}

Received: 22 May 2021 / Accepted: 12 January 2022 / Published online: 26 February 2022

(c) The Author(s) 2022

\begin{abstract}
Recent advances in additive manufacturing have enabled a new generation of electromagnetic applications to flourish. Complex geometries for dielectrics and conductors can now be simulated and rapidly fabricated from digital data. Powder bed fusion of metals is arguably the most widely adopted additive process by industry and can provide intricately-detailed structures in a wide range of high performance alloys. Copper and copper alloys have remained a challenge in this additive process, as the typical laser wavelength (approximately $1070 \mathrm{~nm}$ ) used fails to provide sufficient absorption. Moreover, the high thermal conductivity of copper does not allow for the required heat generation for a stable melt pool. However, the recent commercial introduction of the green laser (515 nm wavelength) is enabling the printing of copper, which is particularly interesting for electrical and electromagnetic applications due to the high electrical conductivity and solderability. This paper describes the use of a green laser powder bed fusion system used to fabricate a complex fractal Sierpinski gasket ground structure with an isolated internal pyramid antenna built simultaneously — within and dielectrically isolated from the external ground element: a ship-in-the-bottle design paradigm. The electromagnetic performance, surface finish, dimensional compliance, and conductivity were measured and reported to inform the design of freestanding, geometrically-complex antennas.
\end{abstract}

Keywords Additive manufacturing · Green laser · Powder bed fusion · Fractal antennas · Copper · Sierpinski gasket

\section{Introduction}

Additive manufacturing (AM) originally enabled rapid prototyping of freeform structures but has more recently graduated to fabricating customized and complex end-use components from high-performance materials for a diverse array of industrial applications. One field that stands to benefit dramatically from AM is electromagnetics, in which unprecedented geometries are now feasible with 3D control of the placement of either conductive or dielectric materials or both together in new geometric topologies [1]. Yet, until recently, direct printing of materials with high electrical conductivity

Kerry Johnson

kjohnson10@student.ysu.edu

1 Youngstown State University, Youngstown, OH 44555, USA

2 Ohio State University, Columbus, OH 43210, USA

3 Trumpf Inc., Plymouth Township, Plymouth, MI 48170, USA

4 University of Texas at El Paso, El Paso, TX 79968, USA has not been possible. Powder bed fusion (PBF) is one of the most widely embraced processes in the industry for customized metal fabrication; nevertheless, commercially-available metals have offered only a fraction of electrical conductivity as compared to traditional electrical manufacturing [2]. However, the introduction of the green laser in PBF is now enabling the fabrication of nearly full-density copper and copper alloy structures.

Antennas have been fabricated for years across many AM processes. Initially, 3D printed antennas largely featured conductive ink deposition on polymer substrates [3-13], enabling complex surface conduction for tunable electromagnetic (EM) characteristics; however, most applications only reached a fraction of the bulk conductivity based on limits on curing temperatures imposed by the polymeric substrates. Alternatively, exclusively polymer deposition (fused filament fabrication, material jetting and vat photopolymerization) have been employed for lensing elements that rely exclusively on dielectric materials, or with doped dielectrics containing conductive particles [14-17]. Building from polymer substrates has the advantages of weight savings and 
inexpensive material, but can come at the expense of performance, depending on the (EM) application [18]. For this reason, metallization of these parts by means of plating, painting and sputtering conductive material, either selectively or fully, can be effective, so long as the surface roughness of the components does not interfere with desired frequencies of interest [19-21]. Requirements of greater non-load-bearing mechanical stability and skin depth limitations motivate the need for fully metallic objects, which can improve components such as waveguides and free-standing antennas [22-25].

Combining both high thermal and electrical conductivity, copper remains one of the most favorable materials for fabricating EM products. Each of the seven methods of AM has been reported to fabricate or include copper alloy structures, surfaces or filaments. Copper wire has been embedded with selective heating in thermoplastics, conductors which retain bulk conductivity [26]. Surface metalization research has been achieved for antennas of all types (slot, fractal, horn, patch, reflectarray, etc.), with applications including radio frequency identification (RFID), thermal management of LEDs, telecommunications and snow-pack monitoring, and microwave waveguide lightweighting [18, 26-47].

Several additive processes are effective at fabricating complete copper structures. Highly precise Vat Photopolymerizable (VPP) metallic slurry-based methods have been developed by Admatec, which result in highly dense and smooth parts, but with the requirement of sintering which results in some shrinkage and porosity. Alternatively, binder jetting has been applied to a diversity of applications, but as studies suggest, these parts can be hampered in both conductivity and thermomechanical performance due to limited densification of green state parts [48, 49]. However, applications have been reported to have less-than-fully-dense foams which may benefit from porosity for lightweighting or impact energy management [50]. Recently, commerciallyavailable systems provide material extrusion 3D printing of polymer filament, including suspended metal powder-enabling the fabrication of green parts that after further debinding and sintering, which can provide nearly-full dense structures. Although all of these processes can result in complex and nearly-full density copper structures, limitations remain in the debinding of thick bulky parts and shrinkage resulting from sintering [51-54].

While all of these AM processes have their associated advantages for electromagnetics in terms of cost and officefriendly printing, $\mathrm{PBF}$ can provide complex metal parts with more than $99 \%$ density with minimal shrinkage, but copper has been a challenge, particularly for laser-based systems. PBF of metals subsumes two processes defined by the fusion source, including (1) electron beam- and (2) laser-based melting. Electron beam melting offers high energy and reliable melting under vacuum to avoid oxidation [55-57], but requires larger powder size distribution, which impacts surface roughness and resolution. In contrast, early attempts to print copper components with laser powder bed fusion (LPBF) were less successful due to reflectivity and insufficient power. Traditional laser systems use red lasers, and while sufficient for metals of lower reflectivity and thermal conductivity, melt pool stability remains a challenge for copper. Increasing the laser power can result in increased spattering as well as energy reflected back toward the lasing system, and at high wavelengths, more contaminants can be incorporated in builds, which can reduce electrical conductivity [58-60]. Even with these shortcomings, researchers have been successful in developing prints in both high purity copper and alloyed components [2, 61-74]. Parts that are dependent on surface finish, like metamaterial latticing and high-frequency electromagnetic designs, have still met standards $[75,76]$. Through these innovations, reasonable results have been obtained, although the introduction of blue and green wavelength lasers is advancing LPBF for structures with improved electrical and thermomechanical properties of printed copper parts [72, 73]. Recently, blue laser systems have begun to resolve the issue of power limitations [77]. New green laser systems, such as the Trumpf TruPrint 1000 Green Edition are well suited for copper and copper alloys.

The objective of this work is to demonstrate the utility of recently-available green laser processing in PBF to create a complex, novel and functional fractal antenna with a standing wave ratio of less than two and a discrepancy of less than $7 \mathrm{MHz}$ between simulation to experimental resonancesall of which can be explained by post-processing assembly steps such as soldering, component alignment, and surface finishing. The 3D printed copper antenna was evaluated in terms of electromagnetic and dimensional performance, as well as manufacturability. All with the aim of informing antenna designers about the potential and limitations of this 3D printing process, capable of creating complex structures with copper and well suited for electromagnetic applications.

\section{Materials and methods}

The copper printing capabilities of the Trumpf TruPrint 1000 Green Edition with a $515 \mathrm{~nm}$ wavelength green laser (Fig. 1) were evaluated with typical figures of merit for electromagnetic evaluation. Surface roughness scans of finished parts were assessed. A desktop Wheatstone bridge setup was assembled for the determination of isotropic conductivity characteristics. A novel Sierpinski gasket antenna was designed with an internal conductor, allowing for the singular printing of the end-use part. The manufactured structure underwent an antenna simulation and was then evaluated for electromagnetic performance. 
Fig. 1 Trumpf TruPrint 1000 green edition with green laser

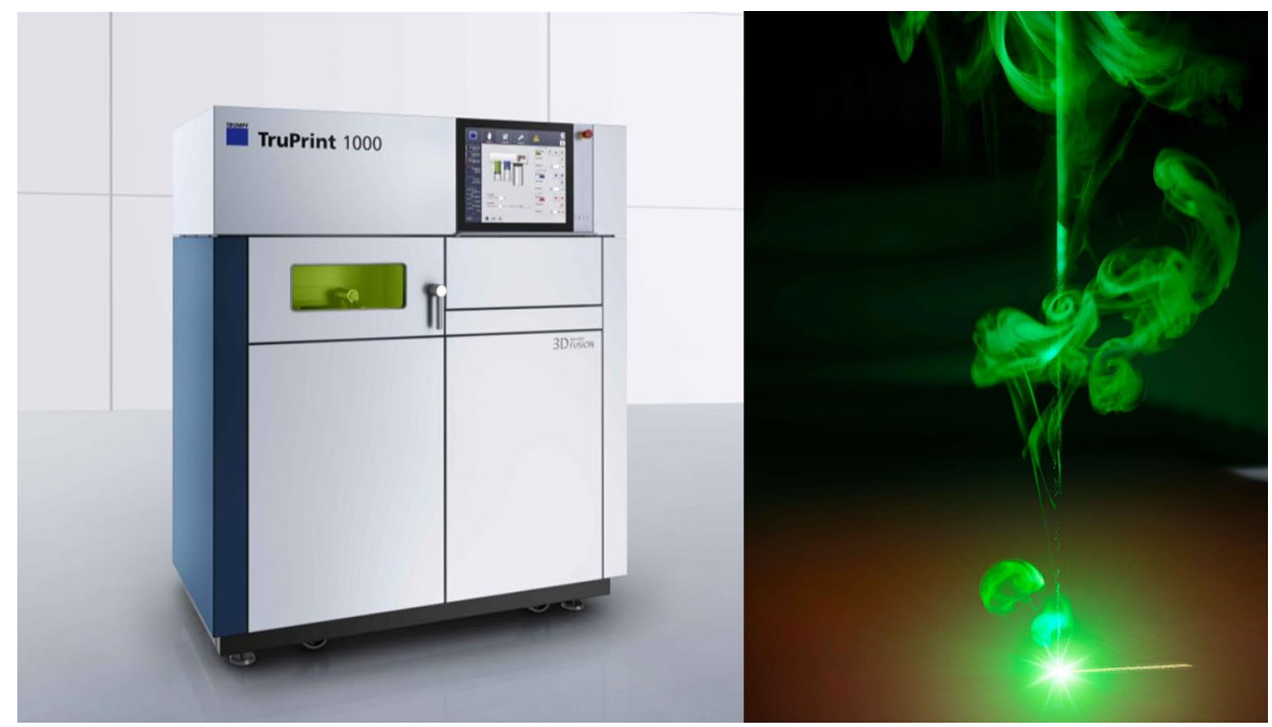

\subsection{TruPrint 1000 with green laser $(515 \mathrm{~nm})$}

The TruPrint 1000 Green Edition printer combines the capabilities of advanced lasers with PBF printing. The TruDisk 1020 is a high-power $515 \mathrm{~nm}$ continuous-wave industrial green lasers system based on a Yb:YAG thin-disk laser platform with intracavity frequency doubling, which delivers a maximum output power of $1 \mathrm{~kW}$ [78]. The system emits a beam with a brightness of $2 \mathrm{~mm} \times \mathrm{mrad}$, transmitted by the beam delivery fiber, is collimated and deflected via a pair of galvanometer scanners, and focused by a f-theta lens to a spot size of $200 \mu \mathrm{m}$ diameter with a top-hat intensity distribution before operating on the $7854 \mathrm{~mm}^{2}$ TruPrint 1000 processing plane. This unique combination is well suited for LPBF printing of both copper and copper alloys. Copper, copper-based alloys, and other high thermal conductivity metals have higher energy absorption, based on molecular bandgap excitation within the metals, at green wavelengths than at the wavelengths associated with red diode lasers used in traditional PBF systems (see Fig. 2). The metal welding process can thus be stabilized with lower reflectivity, keyhole porosity, and balling [78].

The powder used in this study was Hoegenaes $\mathrm{Cu} \mathrm{OFCH}$ powder $99.99 \%$ copper, with a particle size distribution of 15-53 microns. Conductivity measurements of up to $102 \%$ of the International Annealed Copper Standard (IACS) were obtained for the powder. It should be noted that the IACS was established over a century ago, and significant improvements in metallurgical processes have enabled modern manufacturers to exceed the conductivity thresholds established at that time. The system is capable of producing wall thicknesses in the $0.4-0.6 \mathrm{~mm}$ range when scan speed and power settings are controlled [78]. Table 1 provides the system process parameters that were used to build the antenna

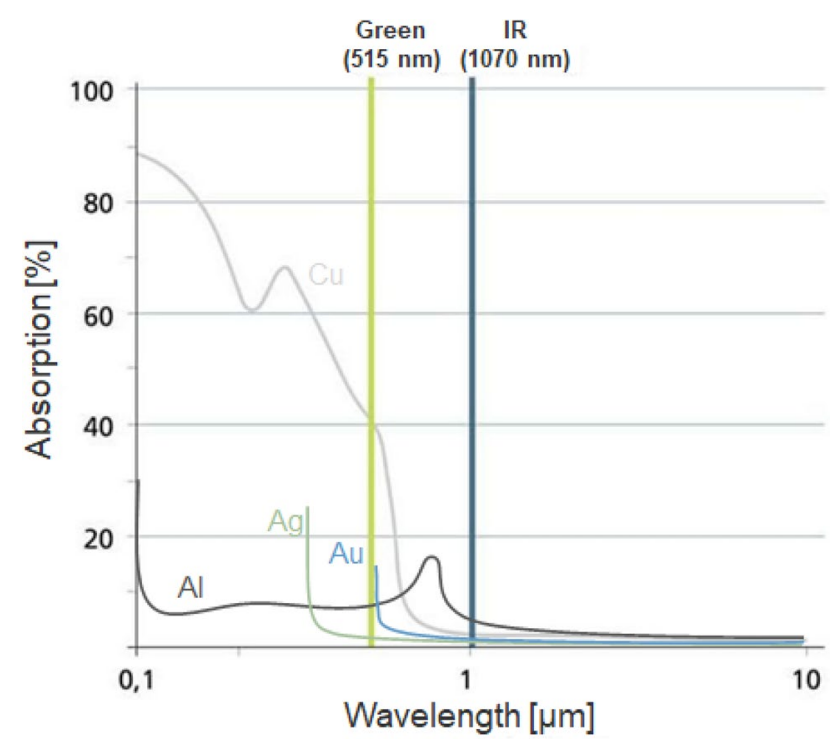

Fig. 2 Comparative absorptivity plot of copper and other conductive metals by wavelength

prototype. This was a standard parameter set that will be optimized for further applications.

Table 1 Laser printing process parameters

\begin{tabular}{ll}
\hline Wavelength $(\mathrm{nm})$ & 515 \\
Power $(\mathrm{W})$ & 485 \\
Scan speed $(\mathrm{mm} / \mathrm{s})$ & 600 \\
Hatch distance $(\mathrm{mm})$ & 0.12 \\
Layer thickness $(\mathrm{mm})$ & 0.03 \\
Inert gas type & Argon \\
\hline
\end{tabular}




\subsection{Dimensional compliance and surface roughness evaluation}

To determine the overall dimensional accuracy of the antenna, the Faro Quantum S ScanArm 3D scans of the print were compared with the parent CAD model from the simulation to determine compliance [79]. Additionally, surface roughness measurements were conducted using the Keyence 3D Optical Profilometer-VR-5000 [80]. Such measurements serve to determine if the AM process is viable for high-frequency devices. For a specific frequency of interest, roughness on the order of approximately $1 / 10$ of the wavelength is generally considered electromagnetically irrelevant. For example, the $2.4 \mathrm{GHz}$ frequency used in many commercial radio applications has a wavelength of $6.5 \mathrm{~cm}$ and, therefore, spatial distortions less than $6.5 \mathrm{~mm}$ are considered immaterial. However, in the case of the antenna fabrication, dimensional compliance is paramount and it is most directly correlated with the resonance. Imperfections on a scale much smaller than the wavelength of interest generally will not impact antenna performance through the skin effect.

\subsection{Antenna design and simulation}

To demonstrate the utility of the green-laser PBF, an antenna geometry was selected that was both novel and complex, leading to the selection of the 3D ship-in-a-bottle Sierpinski gasket design. While other fractal designs, and Sierpinski designs for that matter, have been successfully printed before, this design nests a radiator within a gasket 3D ground plane [11, 23, 37, 38, 81, 82]. Previously, the Sierpinski gasket has been shown to have multiband and electrically small characteristics, with overall band congruence shown to have a dependence on the number of iterations in the fractalization design hierarchy: as the number of iterations approaches infinity, the bands become more mathematically similar [82]. Here, the internal component was positioned by non-conductive adapters on all four faces, strategically maintaining the alignment of the ground plane pyramid symmetrically in the center of the radiating pyramid (see Fig. 3). The dielectric properties of the non-conductive supports were approximated to typical thermoset values in conjunction with the known values of the copper conductor parts in ANSYS HFSS simulations. A canting evaluation was conducted about the orthocenter of the internal pyramidal structure. Rotations about the $\mathrm{x}, \mathrm{y}$, and $\mathrm{z}$ axes were parameterized for low-angle deviations from perfect alignment to perform a misalignment sensitivity analysis. Common metrics of $S_{11}$ and VSWR were taken to characterize antenna transmission.

\subsection{Conductivity (DC) measurement and anisotropy}

To determine the conductivity of the copper printed parts, a Fischer Sigmascope SMP350 was used to measure via the phase-sensitive eddy current method [78]. When properly welded, highly dense parts ( $>99.5 \%$ density) result in an electrical conductivity of $5.8 \times 10^{7} \mathrm{~S} / \mathrm{m}(100( \pm 2) \%$ IACS $)$ and a thermal conductivity of approximately $400 \mathrm{~W} /(\mathrm{m} * \mathrm{~K})$. A Wheatstone bridge test was performed with the antenna treated as the unknown load. Multiple combinations of the terminal points on the antenna geometry were used to account for potential anisotropic conductivity behavior of the part-between layers and within a layer. Given that the antenna build orientation was in an upright position, the base vertices shared the same build layer, so measuring conductivity variations over multiple layers was not feasible in this case. This drove the need to test along all edges between vertices (Fig. 4).

\subsection{Antenna evaluation}

By measuring input impedance, radiation patterns, polarization, gain, specific absorption rate (SAR) and directivity of the antenna, the multiband behavior can be optimized to enhance many commercial applications, including multiband and frequency hopping. Complex input impedance
Fig. 3 Simulation body and picture of a nested Sierpinski gasket dipole with polymer standoffs (gray parts) and SMA connector included

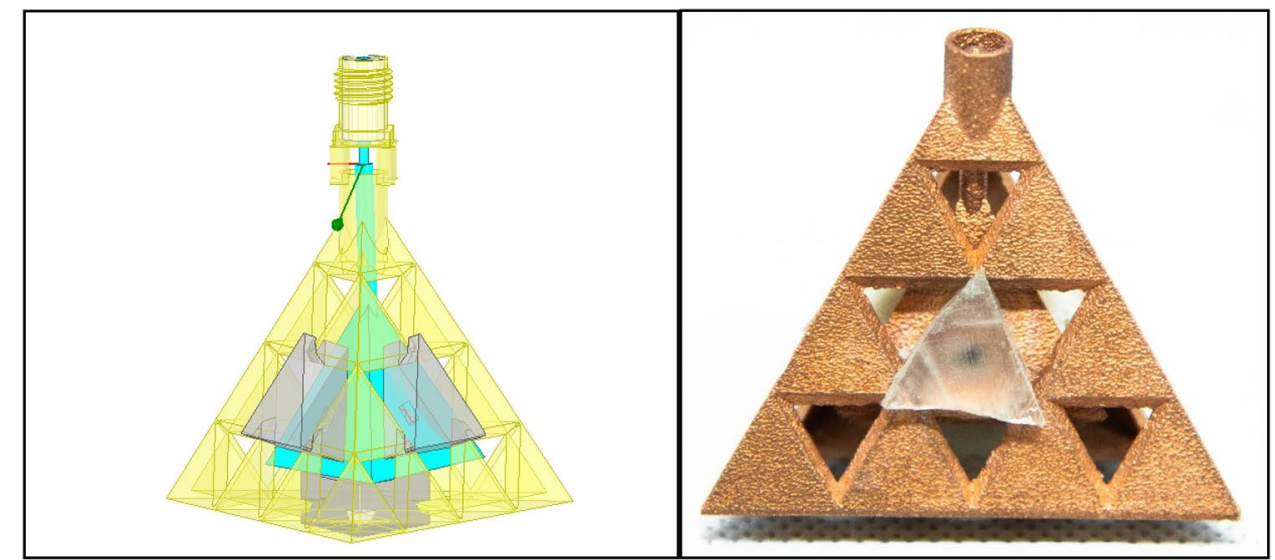




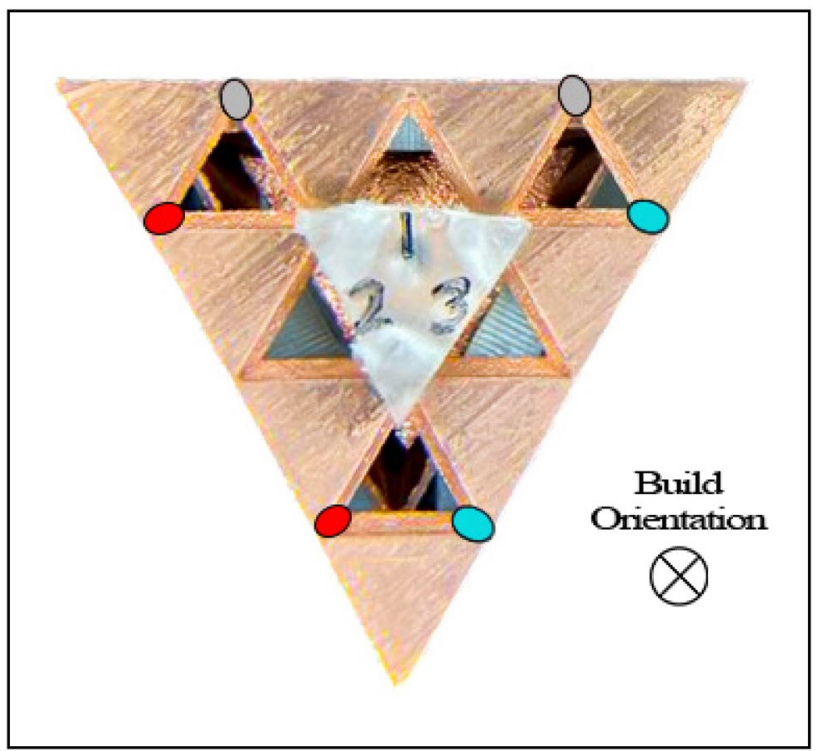

Fig. 4 Conductivity readings were taken from the paired (same colored) points on every face. Every edge of the antenna was evaluated

measurements can provide information on the antenna's reflection characteristics, resonant frequency, radiation efficiency and the need for a matching network if used in the typical $50-\Omega$ circuit [83]. S-parameters describe the input-output relationship between two terminals in an electrical system. Specifically, the $S_{11}$ parameter represents how much power is reflected from the antenna back to the transmitter circuit. If the antenna complex impedance $\left(Z_{L}=Z_{\text {Real }}+j Z_{\text {Imaginary }}\right)$ is equal to the complex conjugate of the line characteristic impedance $\left(Z_{0}\right)$, then the transmission line is said to be "matched". In this case, there is no loss to impedance mismatch reflections and all the power is transferred to the antenna. Qualitatively, the magnitude of the reflection coefficient is the ratio of power the antenna is absorbing and therefore radiating and/or losing to other ohmic losses such as heat dissipation. Direct measurement of the complex input impedance allows the design of the impedance matching network to maximize power delivery to the antenna. For the purposes of this study, antenna impedance was measured without the use of a matching network to give insight on the effects of the design and manufacturing processes on the finished product. Future work includes the design of a matching network, gain, directivity, and radiation pattern measurements to establish the prospective use of such a geometry, which can only be produced through manufacturing methods presented in this work. These elements are more related to the design rather than the manufacturing process.

\section{Results and discussion}

The antenna was reviewed for dimensional and surface abnormalities. While the dimensional accuracy and surface finish were acceptable, the surface roughness was slightly more coarse than traditional LPBF. Additionally, the antenna resonance was in near accordance with the expected simulation results. Lastly, the evaluation of conductive isotropy relative to build orientation showed minimal deviation along nonplanar edges of the conductive geometry.

\subsection{Dimensional compliance and surface roughness}

The antenna was printed successfully without any substantial defects, with support structures for the extreme overhangs preventing any sagging or noticeable warping. The part was shot-blasted with $\mathrm{Al}_{2} \mathrm{O}_{3}$ and glass beads but received no heat treatment, hot isostatic pressing (HIP), or similar postprocessing steps. Additionally, printing resulted in minimal deviation from CAD measurements. A 3D surface scan of the part was taken, and analyzed the extent of surface deviation (Fig. 5) to be a maximum difference between intended and actual surface position of $0.222 \mathrm{~mm}$.

Three dimensional optical profilometry was conducted on the part faces (Fig. 6). The arithmetic mean height $(18.5 \mu \mathrm{m})$ and root mean square height $(24.8 \mu \mathrm{m})$ are reasonable, and future optimization will bring this in line with conventional LPBF values associated with other metals processed with red wavelength lasers [22]. The surface roughness of the antenna has a minimal impact on the conductivity, however, it may change the surface current distributions especially in $\mathrm{K}, \mathrm{Ka}$, and other mm-wave frequency bands, where the surface roughness is comparable to the radio frequency (RF) wavelength. Antenna geometries were designed for optimal performance in the $5 \mathrm{Ghz}$ range, and therefore, For the purpose of this evaluation, the radiation characteristics of this evaluation were constrained to the IEEE $\mathrm{C}$ band. Specifically, the frequency values from 4.0 to $6.5 \mathrm{GHz}$.

\subsection{Antenna evaluation}

For RF evaluation of the antenna, complex impedance measurements for the $S_{11}$ parameter were taken using the Rigol $^{\text {TM }}$ RSA5065N, Real-Time Spectrum Analyzer with Vector Network Analysis (VNA) (Fig. 7). A 50-Ohm SMA connector was soldered to the antenna and connected directly to the VNA 50-Ohm port via the Mini-Circuits ${ }^{\mathrm{TM}}$ NM-SM50 + SMA to N adapter.

The $S_{11}$ calculation from the complex impedance measurement revealed the antenna to be most resonant at $5.569 \mathrm{GHz}$, exhibiting a return loss of $-9.323 \mathrm{~dB}$ 


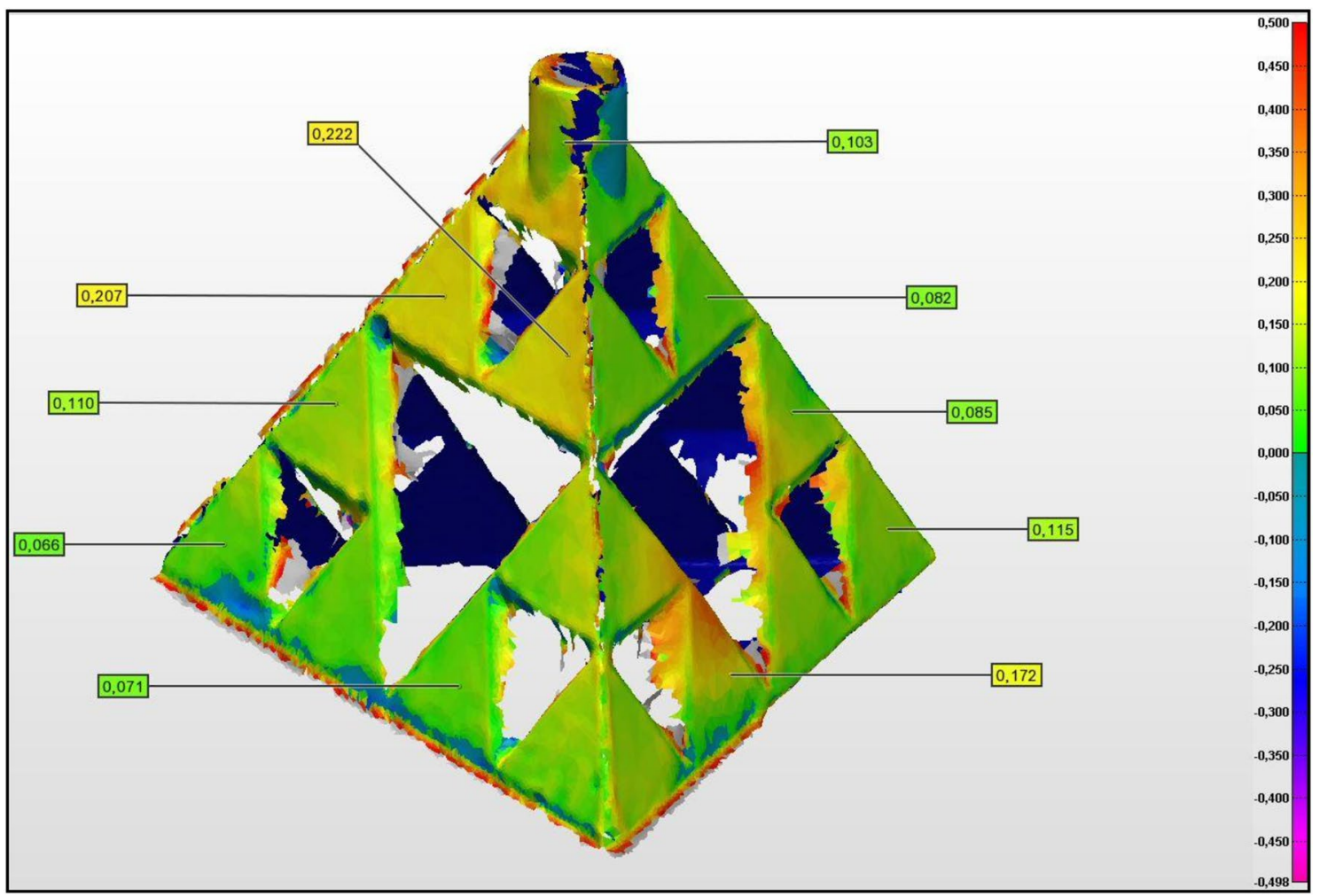

Fig. 5 3D scan - compliance to design intent

Fig. 6 A full surface 3D optical profilometry

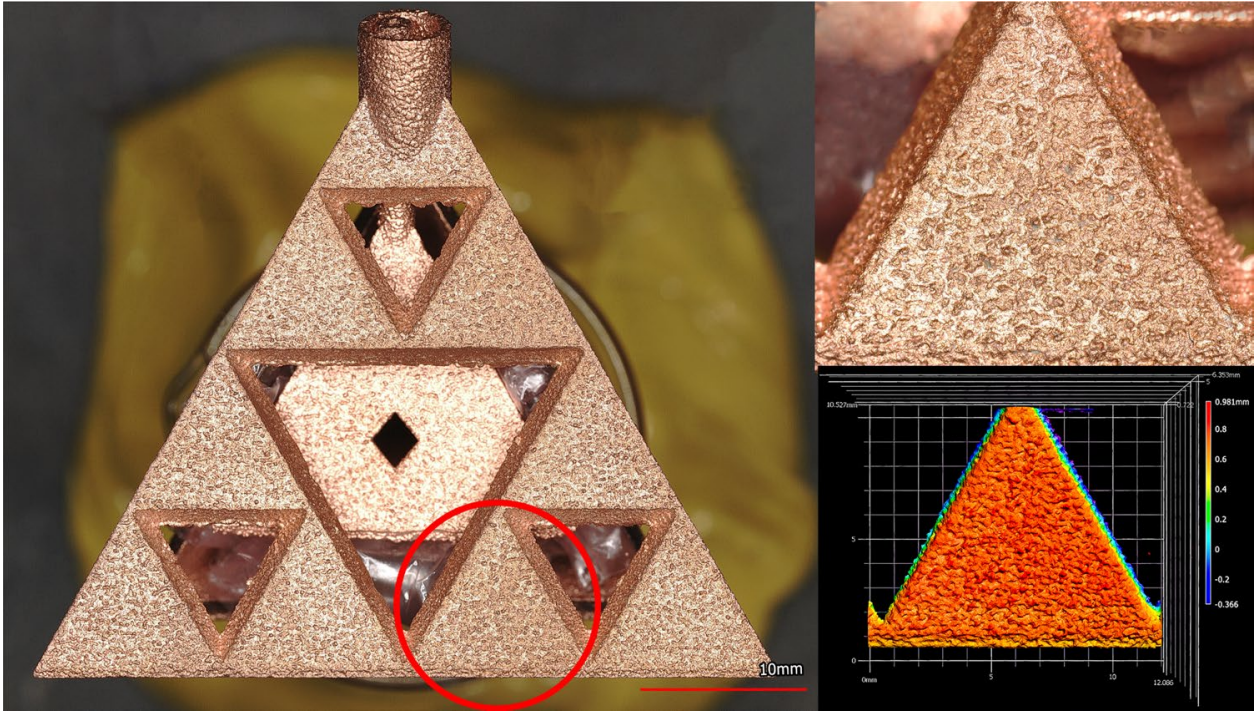

(Fig. 8). This compared to the $S_{11}$ minima of $-2.963 \mathrm{~dB}$ at $5.579 \mathrm{GHz}$ for the HFSS model suggested a $10 \mathrm{MHz}$ delta in expected minimum resonance from design simulation to physical measurement. There were clear similarities in the frequency of minimum reflectance and overall shape between measured and simulated $S_{11}$ parameters. Additionally, the $S_{11}$ parameter of $-9.323 \mathrm{~dB}$ translated to a voltage standing wave ratio (VSWR) of 2.039. These measurements encourage further study of the antenna's RF characteristics such as $S_{21}$ parameters leading to efficiency, radiation pattern, directivity, and gain.

When converting $S_{11}$ from $\mathrm{dB}$ to linear units, it can be seen that a fraction of the total signal is reflected. The measured return loss suggests that approximately $88 \%$ of the transmitted power is absorbed by the antenna when connected to a $50-\Omega$ termination. This does not imply however 
Fig. 7 Direct connection of the antenna to the VNA

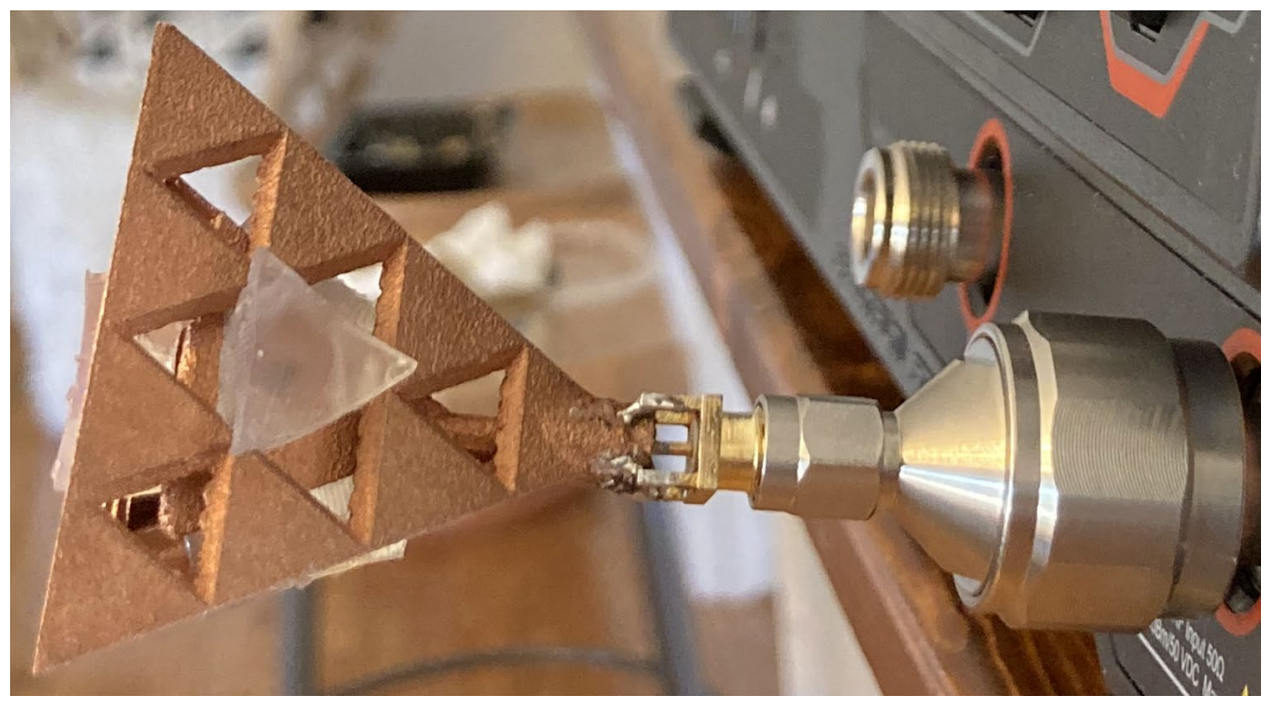

Fig. 8 Measured versus simulated $S_{11}$ return loss

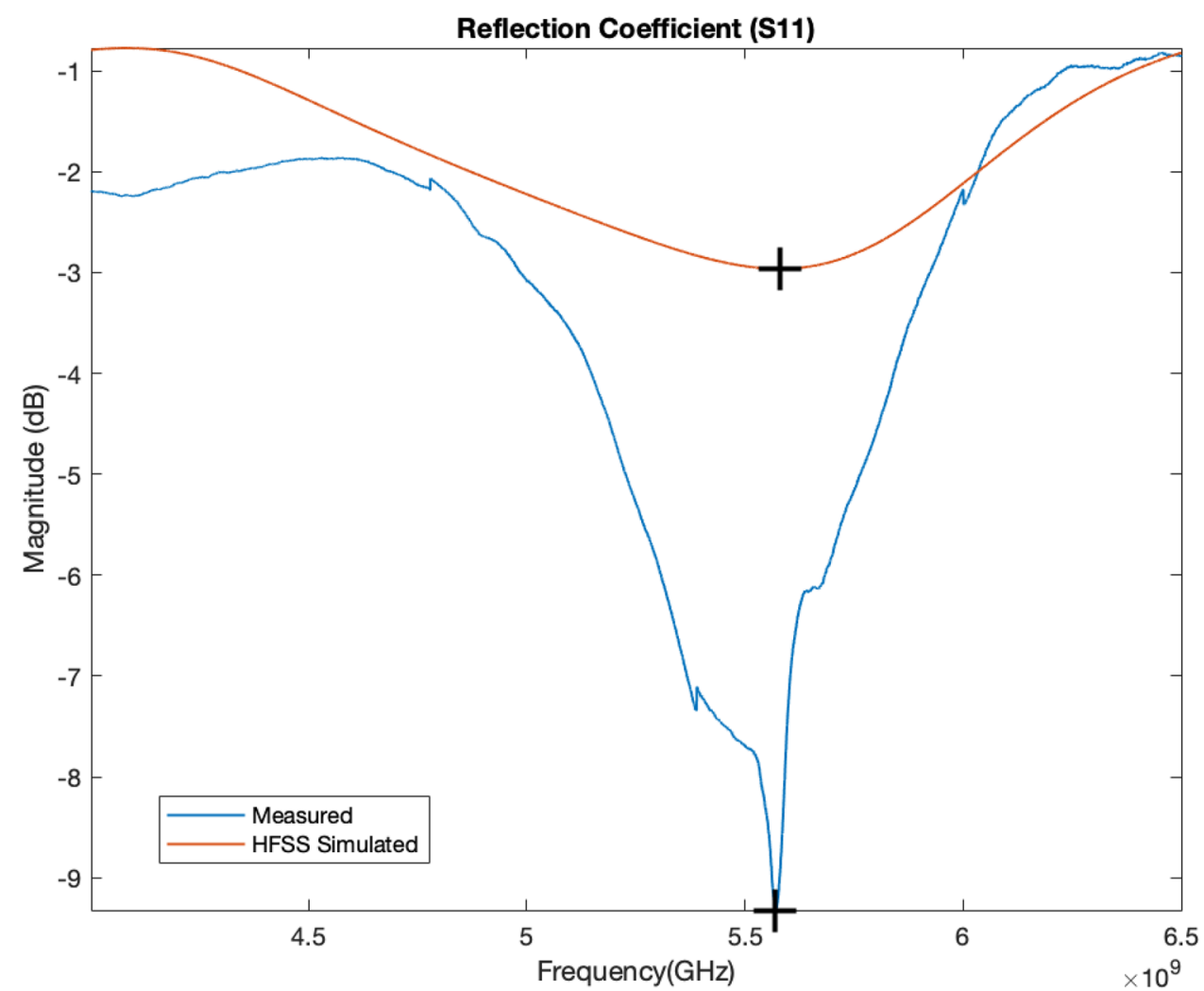

that $\sim 880 \mathrm{~mW}$ of $1 \mathrm{~W}$ transmitted power is radiated by this particular antenna. Ohmic losses must be taken into consideration when calculating the transmission efficiency of the antenna. As seen in the antenna Smith Chart (Fig. 9), there is an impedance mismatch in the antenna input and the VNA port. There is also a rotation between the simulated and measured impedances. Looking at the plot, it could be said that the measured data being less concentrated in the upper half-circle implies that the simulation predicted more inductive behavior than was actually measured. The rotation itself implies that the behavior of the measured antenna is congruent to that of the predicted model but shifted in frequency. The direct connection to the VNA via RF adapter (only an adapter separating the antenna from the port: sans transmission line) may be affecting the results of the measured input impedance. Impedance mismatches can be remedied through the use of a matching network. Antenna impedance is a direct result of the design methodology and 


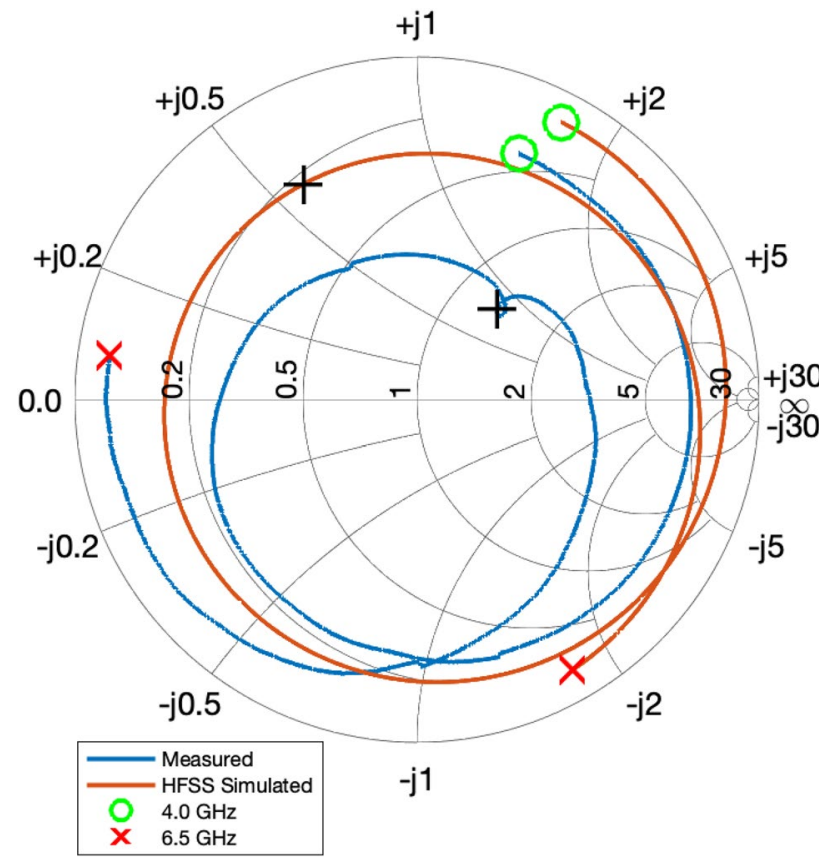

Fig. 9 Measured versus simulated S parameter Smith Chart

geometry, material selection, manufacturing and assembly processes. Without the use of a matching network, antenna performance degradation is to be expected. However, it was decided not to employ a matching network in this study as not to influence the raw performance characteristic of the novel manufacturing process.

The discrepancies between simulated and measured reflection coefficient magnitudes at $\sim 5.57 \mathrm{GHz}$ has yet to be determined. However, it is hypothesized that the main radiation mechanism is from fringing fields - with orthogonal lines between the inner and outer pyramid [84]. Through simulation analysis, it was found that any canting or offalignment of the two pyramids can have a direct impact on radiation characteristics and therefore the perceived input impedance. Separation measurements between the pyramidal bases were made on the antenna (Fig. 10) and replicated in the HFSS model. These iterations lead to a stronger correlation of measurement parameters displayed in this work.

\subsection{Conductivity}

In evaluation of the potential for anisotropic effects on conductivity, a Wheatstone bridge test was performed on the antenna. Statistical data from the Wheatstone bridge was recorded for the assessment of the hypothesis that conductivity did not depend on the building orientation of this anisotropic manufactured structure. At the time of the test, the dipoles were disconnected, but an SMA connector had

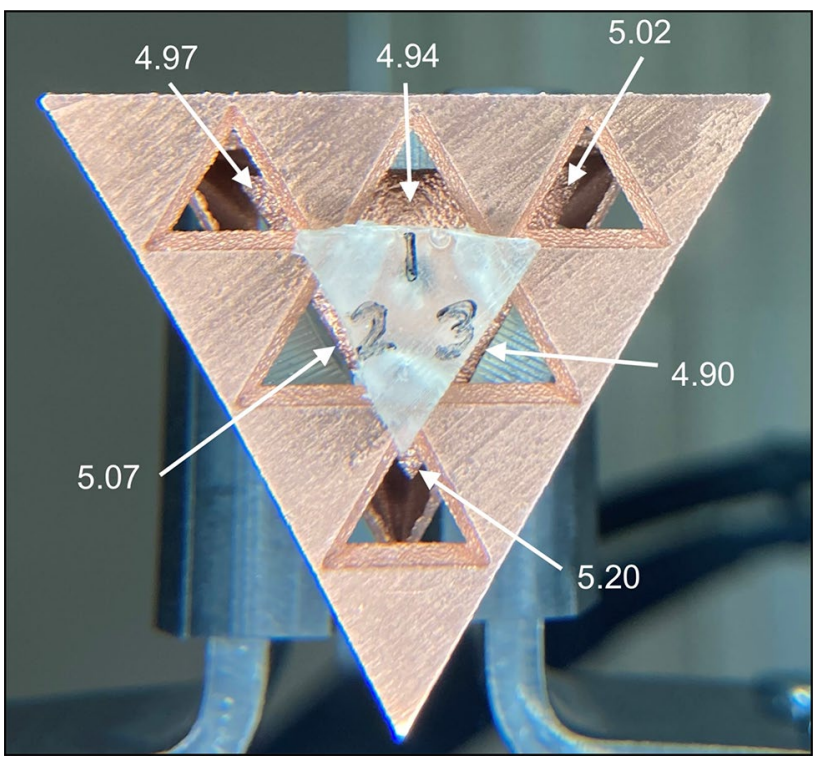

Fig. 10 Separation between lower surfaces of inner and outer triangles in millimeters

been soldered to form the coaxial junction. Measurements for resistance were taken along four edges in the manner illustrated by Fig. 3, where shared edges were denoted by subscripts (Table 2). A single factor ANOVA evaluation proved that the test voltages found each edge resistance value measured for the bulk component to be reliable (Table 3). The implication being that the build orientation has minimal effects on the isotropic nature of the conductivity. For new geometries, antenna designers can ignore the influence of layer direction at least in terms of conductivity. However, surface roughness and stair stepping are features that may still need to be considered in terms of conductivity in these novel 3D printed antennas.

\section{Conclusions}

A nested Sierpinski gasket antenna was successfully printed using the Trumpf TruPrint 1000 Green Edition L-PBF system. Greater capabilities exist with systems of smaller build volumes, but a geometrically similar Sierpinski antenna of the necessary size would radiate beyond the capabilities of available testing equipment. Soldering of the RF feed components may have caused a frequency shift of the antenna, as copper thermal conductivity requires a high heat soldering environment and properly matched flux to avoid oxidation. Future work involving matching components will be tested for increasing antenna resonance. High conductivity copper components will be fabricated to further develop freeform electromagnetic and thermal management capabilities. A 
Table 2 Wheatstone ANOVA approximated antenna resistance

\begin{tabular}{lrrllll}
\hline Wheatstone ANOVA voltage readings (grand mean $\left.=1.019 \times 10^{-7}\right) R_{1}=7.5 \mathrm{k} \Omega ; R_{2}=75 \mathrm{~m} \Omega$ \\
\hline Edge Under Test & $N$ & $\begin{array}{l}\text { Mean detector } \\
\text { voltage }(\mu \mathrm{V})\end{array}$ & Std. dev & Std. error & $R_{3}(\Omega)$ & $R_{\text {antenna }}(\mathrm{m} \Omega)$ \\
& 76 & -80.902 & 0.0002239736446 & 0.00002569153903 & 122.4 & 1.224 \\
Edge $_{23}$ & 74 & 37.175 & 0.0001827358052 & 0.00002124260587 & 111.2 & 1.112 \\
Edge $_{12}$ & 187 & -56.365 & 0.0002330991522 & 0.00001704589821 & 113.8 & 1.138 \\
Edge $_{11}$ & 83 & 37.679 & 0.0002149101348 & 0.00002358945191 & 116 & 1.160 \\
Edge $_{22}$ & 354 & 86.835 & 0.0002445523742 & 0.00001299781204 & 113 & 1.130 \\
Edge $_{33}$ & 82 & 62.804 & 0.0002638087767 & 0.00002913280581 & 112.9 & 1.129 \\
Edge $_{13}$ & & & & & \\
\hline
\end{tabular}

Table 3 Single Factor ANOVA test for resistance variance demonstrating isotropic behavior

\begin{tabular}{lllllll}
\hline \multicolumn{2}{l}{ ANOVA resistance test summary $(a=0.001)$} \\
\hline Source & DF & Sum of squares SS & MS & $F$-stat & $P$-value & $F$ crit \\
\hline Between groups & 5 & $3.57 \mathrm{E}-06$ & $7.14 \mathrm{E}-07$ & 12.95071 & $3.67 \mathrm{E}-12$ & 4.145531 \\
Within groups & 850 & $4.68 \mathrm{E}-05$ & $5.51 \mathrm{E}-08$ & & & \\
Total & 855 & $5.04 \mathrm{E}-05$ & & & & \\
\hline
\end{tabular}

more rigorous follow-up evaluation is required for parts of lower complexity, however, statistical evaluations show a high confidence in the isotropic behavior of conductivity.

- The fabrication of a geometrically-complex and functional antenna was demonstrated with a green LPBF system.

- Preliminary evaluation shows good simulation-tomeasurement agreement to validate the use of sophisticated 3D electromagnetic simulations for exploring the enhanced design space afforded by additive manufacturing-particularly of highly-conductive metals.

- Although the surface roughness was greater than previously printed components on the system, for the sake of the evaluated antenna frequency band, minimal effects on resonance were found.

- Ultimately, evaluations concluded that conductivity is not build-orientation dependent and is isotropic, as small differences in measured resistances were the result of measurement precision rather than actual regional surface roughness. Antenna designers can ignore conductivity effects based on how the part is oriented during fabrication.

- Surface roughness was not highly dependent on the build orientation, but stair-stepping could require consideration for frequencies at or greater than the $K_{\mathrm{a}}$ band $(26.5 \mathrm{GHz}$ and above). Future work will endeavor to optimize printing parameters.

Funding Funfing were provided by Murchison Chair UTEP and Ohio Federal Research Network.

\section{Declarations}

Conflict of interest On behalf of all authors, the corresponding author states that there is no conflict of interest.

Open Access This article is licensed under a Creative Commons Attribution 4.0 International License, which permits use, sharing, adaptation, distribution and reproduction in any medium or format, as long as you give appropriate credit to the original author(s) and the source, provide a link to the Creative Commons licence, and indicate if changes were made. The images or other third party material in this article are included in the article's Creative Commons licence, unless indicated otherwise in a credit line to the material. If material is not included in the article's Creative Commons licence and your intended use is not permitted by statutory regulation or exceeds the permitted use, you will need to obtain permission directly from the copyright holder. To view a copy of this licence, visit http://creativecommons.org/licenses/by/4.0/.

\section{References}

1. Kokkinis D, Schaffner M, Studart AR (2015) Multimaterial magnetically assisted 3D printing of composite materials. Nat Commun 6:8643

2. El-Wardany TI, She Y, Jagdale VN, Garofano JK, Liou JJ, Schmidt WR (2018) Challenges in three-dimensional printing of highconductivity copper. J Electron Packag. https://doi.org/10.1115/1. 4039974

3. Smith PJ, Shin D-Y, Stringer JE, Derby B, Reis N (2006) Direct ink-jet printing and low temperature conversion of conductive silver patterns. J Mater Sci 41:4153-4158

4. Adams JJ, Duoss EB, Malkowski TF, Motala MJ, Ahn BY, Nuzzo RG et al (2011) Conformal printing of electrically small antennas on three-dimensional surfaces. Adv Mater 23:1335-1340 
5. Ahn BY, Walker SB, Slimmer SC, Russo A, Gupta A, Kranz S et al (2011) Planar and three-dimensional printing of conductive inks. J Vis Exp. https://doi.org/10.3791/3189

6. Paulsen JA, Renn M, Christenson K, Plourde R (2012) Printing conformal electronics on 3D structures with Aerosol Jet technology. 2012 Future of instrumentation international workshop (FIIW) Proceedings. ieeexplore.ieee.org; pp. 1-4

7. Ahmadloo M, Mousavi P (2013) A novel integrated dielectricand-conductive ink 3D printing technique for fabrication of microwave devices. 2013 IEEE MTT-S international microwave symposium digest (MTT). ieeexplore.ieee.org; pp. 1-3

8. Nate KA, Hester J, Isakov M, Bahr R, Tentzeris MM (2015) A fully printed multilayer aperture-coupled patch antenna using hybrid 3D/inkjet additive manufacturing technique. 2015 European microwave conference (EuMC). ieeexplore.ieee.org; pp. 610-613

9. Nassar IT, Weller TM, Tsang H (2014) A 3-D printed miniaturized logperiodic dipole antenna. 2014 IEEE antennas and propagation society international symposium (APSURSI). ieeexplore.ieee.org; pp. 11-12

10. Nassar IT, Weller TM, Tsang H (2014) 3-D printed antenna arrays for harmonic radar applications. Wireless and Microwave Technology Conference (WAMICON), 2014 IEEE 15th Annual. ieeexplore.ieee.org; pp. 1-4

11. Smith K, Adams RS (2018) A broadband 3D printed fractal tree monopole antenna. Prog Electromagn Res B Pier B 86:17-28

12. Chen Q, Chen X, Xu K (2017) 3-D printed fabry-pérot resonator antenna with paraboloid-shape superstrate for wide gain bandwidth. NATO Adv Sci Inst Ser E Appl Sci 7:1134

13. Castro AT, Sharma SK (2017) A triple mode waveguide corrugated horn antenna using 3D printing technology. 2017 IEEE International Symposium on Antennas and Propagation USNC/ URSI national radio science meeting. ieeexplore.ieee.org; pp. $1235-1236$

14. Liang M, Ng W, Chang K, Gbele K, Gehm ME, Xin H (2014) A 3-D luneburg lens antenna fabricated by polymer jetting rapid prototyping. IEEE Trans Antennas Propag 62:1799-1807

15. Mirzaee M, Noghanian S, Wiest L, Chang I (2015) Developing flexible 3D printed antenna using conductive ABS materials. 2015 IEEE international symposium on antennas and propagation USNC/URSI national radio science meeting; pp. 1308-1309

16. Ketterl TP, Vega Y, Arnal NC, Stratton JWI, Rojas-Nastrucci EA, Córdoba-Erazo MF et al (2015) A $2.45 \mathrm{GHz}$ phased array antenna unit cell fabricated using 3-D multi-layer direct digital manufacturing. IEEE Trans Microw Theory Tech 63:4382-4394

17. McKerricher G, Titterington D, Shamim A (2016) A fully inkjetprinted 3-D honeycomb-inspired patch antenna. IEEE Antennas Wirel Propag Lett 15:544-547

18. Geterud EG, Bergmark P, Yang J (2013) Lightweight waveguide and antenna components using plating on plastics. 2013 7th European conference on antennas and propagation (EuCAP). ieeexplore.ieee.org; pp. 1812-1815

19. Nayeri P, Liang M, Sabory-Garcia RA, Tuo M, Yang F, Gehm M et al (2014) 3D printed dielectric reflectarrays: low-cost high-gain antennas at sub-millimeter waves. IEEE Trans Antennas Propag 62:2000-2008

20. Hoel KV, Kristoffersen S, Moen J, Holm G, Lande TS (2016) Characterization of a 3D printed wideband waveguide and horn antenna structure embedded in a UAV wing. 2016 10th European conference on antennas and propagation (EuCAP); pp. 1-4

21. Rohrdantz B, Rave C, Jacob AF (2016) 3D-printed low-cost, lowloss microwave components up to $40 \mathrm{GHz}$. 2016 IEEE MTT-S international microwave symposium (IMS), pp. 1-3

22. Decrossas E, Reck T, Lee C, Jung-Kubiak C, Mehdi I, Chattopadhyay $\mathrm{G}$ (2016) Evaluation of 3D printing technology for corrugated horn antenna manufacturing. 2016 IEEE international symposium on electromagnetic compatibility (EMC). ieeexplore. ieee.org; pp. 251-255

23. Shamvedi D, McCarthy OJ, O'Donoghue E, O'Leary P, Raghavendra R (2017) 3D metal printed sierpinski gasket antenna. 2017 International conference on electromagnetics in advanced applications (ICEAA), pp. 633-636

24. Peverini OA, Lumia M, Calignano F, Addamo G, Lorusso M, Ambrosio EP et al (2017) Selective laser melting manufacturing of microwave waveguide devices. Proc IEEE 105:620-631

25. Huang GL, Zhou SG, Chio TH, Yeo TS (2016) Fabrication of a high-efficiency waveguide antenna array via direct metal laser sintering. IEEE Antennas Wirel Propag Lett 15:622-625

26. MacDonald E, Wicker R (2016) Multiprocess 3D printing for increasing component functionality. Science. https://doi.org/10. $1126 /$ science.aaf 2093

27. McKerricher G, Nafe A, Shamim A (2015) Lightweight 3D printed microwave waveguides and waveguide slot antenna. 2015 IEEE international symposium on antennas and propagation USNC/URSI national radio science meeting, pp. 1322-1323

28. Huang Y, Gong X, Hajela S, Chappell WJ (2005) Layer-by-layer stereolithography of three-dimensional antennas. 2005 IEEE antennas and propagation society international symposium. ieeexplore.ieee.org; Vol. 1A, pp. 276-279

29. Espalin D, Muse DW, MacDonald E, Wicker RB (2014) 3D printing multifunctionality: structures with electronics. Int J Adv Manuf Technol 72:963-978

30. Kim OS (2014) Rapid prototyping of electrically small spherical wire antennas. IEEE Trans Antennas Propag 62:3839-3842

31. O'Brien JM, Grandfield JE, Mumcu G, Weller TM (2015) Miniaturization of a spiral antenna using periodic Z-plane meandering. IEEE Trans Antennas Propag 63:1843-1848

32. Sage GPL (2016) 3D printed waveguide slot array antennas. IEEE Access 4:1258-1265

33. Liang M, Xin H (2016) Three-dimensionally printed/additive manufactured antennas. In: Chen ZN, Liu D, Nakano H, Qing X, Zwick T (Eds). Handbook of antenna technologies. Springer Singapore; pp. 661-697

34. Shemelya CM, Zemba M, Kief C, Espalin D, Wicker RB, MacDonald E (2016) Multi-layer off-axis patch antennas fabricated using polymer extrusion 3D printing. 2016 10th European conference on antennas and propagation (EuCAP). ieeexplore.ieee.org; pp. $1-5$

35. Yung WKC, Sun B, Huang J, Jin Y, Meng Z, Choy HS et al (2016) Photochemical copper coating on 3D printed thermoplastics. Sci Rep 6:31188

36. Chen BJ, Yi H, Ng KB, Qu SW, Chan CH (2016) 3D printed reflectarray antenna at $60 \mathrm{GHz}$. 2016 International symposium on antennas and propagation (ISAP); pp. 92-93

37. Bahr RA, Fang Y, Su W, Tehrani B, Palazzi V, Tentzeris MM (2017) Novel uniquely 3D printed intricate Voronoi and fractal 3D antennas. 2017 IEEE MTT-S international microwave symposium (IMS). ieeexplore.ieee.org; pp. 1583-1586

38. Jun SY, Sanz-Izquierdo B, Parker EA, Bird D, McClelland A (2017) Manufacturing considerations in the 3-D printing of fractal antennas. IEEE Trans Compon Packag Manuf Technol 7:1891-1898

39. Angel K, Tsang HH, Bedair SS, Smith GL, Lazarus N (2018) Selective electroplating of 3D printed parts. Addit Manuf 20:164-172

40. Colella R, Michel A, Catarinucci L (2018) Compact 3-D-printed circularly polarized antenna for handheld UHF RFID readers. IEEE Antennas Wirel Propag Lett 17:2021-2025

41. Vu MC, Jeong TH, Kim JB, Choi WK, Kim DH, Kim SR (2021) 3D printing of copper particles and poly(methyl methacrylate) beads containing poly(lactic acid) composites for enhancing 
thermo-mechanical properties. J Appl Polym Sci 138(5):49776. https://doi.org/10.1002/app.49776

42. Teniente J, Iriarte JC, Caballero R, Valcázar D, Goñi M, Martínez A (2018) 3-D printed horn antennas and components performance for space and telecommunications. IEEE Antennas Wirel Propag Lett 17:2070-2074

43. Espin-Lopez PF, Pasian M, Alaimo G, Marconi S, Auricchio F, Heinänen V et al (2018) 3-D printed antenna for snowpack monitoring. IEEE Antennas Wirel Propag Lett 17:2109-2113

44. Kim MJ, Cruz MA, Ye S, Gray AL, Smith GL, Lazarus N et al (2019) One-step electrodeposition of copper on conductive 3D printed objects. Addit Manuf 27:318-326

45. Radha SM, Shin G, Park P, Yoon I (2020) Realization of electrically small, low-profile quasi-isotropic antenna using $3 \mathrm{D}$ printing technology. IEEE Access 8:27067-27073

46. Gu C, Gao S, Fusco V, Gibbons G, Sanz-Izquierdo B, Standaert A et al (2020) A D-band 3D-printed antenna. IEEE Trans Terahertz Sci Technol 10:433-442

47. Lopez AG, Eel C, Chandra R, Johansson AJ (2103) Optimization and fabrication by $3 \mathrm{D}$ printing of a volcano smoke antenna for UWB applications. 2013 7th European conference on antennas and propagation (EuCAP). ieeexplore.ieee.org; pp. 1471-1473

48. Bai Y, Williams CB (2015) An exploration of binder jetting of copper. Rapid Prototyp J 39:88

49. Kumar AY, Wang J, Bai Y, Huxtable ST, Williams CB (2019) Impacts of process-induced porosity on material properties of copper made by binder jetting additive manufacturing. Mater Des 182:108001

50. Miyanaji H, Ma D, Atwater MA, Darling KA, Hammond VH, Williams CB (2020) Binder jetting additive manufacturing of copper foam structures. Addit Manuf 32:100960

51. Chen X, Liu X, Ouyang M, Chen J, Taiwo O, Xia Y et al (2019) Multi-metal 4D printing with a desktop electrochemical 3D printer. Sci Rep 9:3973

52. Ren L, Zhou X, Song Z, Zhao C, Liu Q, Xue J et al (2017) Process parameter optimization of extrusion-based 3D metal printing utilizing PW-LDPE-SA binder system. Materials 10:305

53. Yan X, Wang C, Xiong W, Hou T, Hao L, Tang D (2018) Thermal debinding mass transfer mechanism and dynamics of copper green parts fabricated by an innovative $3 \mathrm{D}$ printing method. RSC Adv 8:10355-10360

54. Singh G, Missiaen J-M, Bouvard D, Chaix J-M (2021) Copper extrusion 3D printing using metal injection moulding feedstock: analysis of process parameters for green density and surface roughness optimization. Addit Manuf 38:101778

55. Murr LE, Martinez E, Amato KN, Gaytan SM, Hernandez J, Ramirez DA et al (2012) Fabrication of metal and alloy components by additive manufacturing: examples of 3D materials science. $\mathbf{J}$ Market Res 1:42-54

56. Ledford C, Rock C, Tung M, Wang H, Schroth J, Horn T (2020) Evaluation of electron beam powder bed fusion additive manufacturing of high purity copper for overhang structures using in-situ real time backscatter electron monitoring. Proced Manuf 48:828-838

57. Guschlbauer R, Momeni S, Osmanlic F, Körner C (2018) Process development of $99.95 \%$ pure copper processed via selective electron beam melting and its mechanical and physical properties. Mater Charact 143:163-170

58. Jadhav SD, Dadbakhsh S, Goossens L, Kruth J-P, Van Humbeeck J, Vanmeensel K (2019) Influence of selective laser melting process parameters on texture evolution in pure copper. J Mater Process Technol 270:47-58

59. Heider A, Sollinger J, Abt F, Boley M, Weber R, Graf T (2013) High-speed X-ray analysis of spatter formation in laser welding of copper. Phys Proced 41:112-118
60. Li S, Chen G, Katayama S, Zhang Y (2014) Relationship between spatter formation and dynamic molten pool during high-power deep-penetration laser welding. Appl Surf Sci 303:481-488

61. Tran TQ, Chinnappan A, Lee JKY, Loc NH, Tran LT, Wang G et al (2019) 3D printing of highly pure copper. Metals 9:756

62. Silbernagel C, Gargalis L, Ashcroft I, Hague R, Galea M, Dickens $\mathrm{P}$ (2019) Electrical resistivity of pure copper processed by medium-powered laser powder bed fusion additive manufacturing for use in electromagnetic applications. Addit Manuf 29:100831

63. Chueh Y-H, Wei C, Zhang X, Li L (2020) Integrated laser-based powder bed fusion and fused filament fabrication for three-dimensional printing of hybrid metal/polymer objects. Addit Manuf 31:100928

64. Jahns K, Bappert R, Böhlke P, Krupp U (2020) Additive manufacturing of $\mathrm{CuCr} 1 \mathrm{Zr}$ by development of a gas atomization and laser powder bed fusion routine. Int J Adv Manuf Technol 107:2151-2161

65. Zhang X, Chueh Y-H, Wei C, Sun Z, Yan J, Li L (2020) Additive manufacturing of three-dimensional metal-glass functionally gradient material components by laser powder bed fusion with in situ powder mixing. Addit Manuf 33:101113

66. Lindström V, Liashenko O, Zweiacker K, Derevianko S, Morozovych V, Lyashenko Y et al (2020) Laser powder bed fusion of metal coated copper powders. Materials. https://doi.org/10.3390/ ma13163493

67. Constantin L, Wu Z, Li N, Fan L, Silvain J-F, Lu YF (2020) Laser 3D printing of complex copper structures. Addit Manuf 35:101268

68. Balzarotti R, Bisaccia A, Tripi MC, Ambrosetti M, Groppi G, Tronconi E (2020) Production and characterization of copper periodic open cellular structures made by $3 \mathrm{D}$ printing-replica technique. J Adv Manuf Process 2:e10068

69. Jadhav SD, Dhekne PP, Dadbakhsh S, Kruth J-P, Van Humbeeck J, Vanmeensel K (2020) Surface modified copper alloy powder for reliable laser-based additive manufacturing. Addit Manuf 35:101418

70. Chueh Y-H, Zhang X, Ke JC-R, Li Q, Wei C, Li L (2020) Additive manufacturing of hybrid metal/polymer objects via multiplematerial laser powder bed fusion. Addit Manuf 36:101465

71. Jadhav SD, Fu D, Deprez M, Ramharter K, Willems D, Van Hooreweder B et al (2020) Highly conductive and strong $\mathrm{CuSn} 0.3$ alloy processed via laser powder bed fusion starting from a tincoated copper powder. Addit Manuf 36:101607

72. Lassègue $\mathrm{P}$, Salvan $\mathrm{C}, \mathrm{De}$ Vito $\mathrm{E}$, Soulas R, Herbin M, Hemberg A et al (2021) Laser powder bed fusion (L-PBF) of $\mathrm{Cu}$ and $\mathrm{CuCrZr}$ parts: influence of an absorptive physical vapor deposition (PVD) coating on the printing process. Addit Manuf 39:101888

73. Robinson J, Arjunan A, Stanford M, Lyall I, Williams C (2021) Effect of silver addition in copper-silver alloys fabricated by laser powder bed fusion in situ alloying. J Alloys Compd 857:157561

74. Gargalis L, Ye J, Strantza M, Rubenchik A, Murray JW, Clare AT et al (2021) Determining processing behaviour of pure $\mathrm{Cu}$ in laser powder bed fusion using direct micro-calorimetry. J Mater Process Technol 294:117130

75. Zhang B, Zhan Z, Cao Y, Gulan H, Linnér P, Sun J et al (2016) Metallic 3-D printed antennas for millimeter- and submillimeter wave applications. IEEE Trans Terahertz Sci Technol 6:592-600

76. Xie Y, Ye S, Reyes C, Sithikong P, Popa B-I, Wiley BJ et al (2017) Microwave metamaterials made by fused deposition 3D printing of a highly conductive copper-based filament. Appl Phys Lett 110:181903

77. Chen X, Ren D, Wu Y, Jin D, Duan Y, Song W et al. (2021) kWlevel high brightness blue diode laser. High-power diode laser technology XIX. International society for optics and photonics; p. $116680 \mathrm{I}$ 
78. Wagenblast P, Myrell A, Thielmann M, Scherbaum T, Coupek D. TruPrint 1000 green edition white paper. 2020

79. FARO Quantum Max ScanArms with Laser Line Probes. Available: https://www.faro.com/en/Products/Hardware/ScanArms. Accesed 20 Nov 2021

80. Keyence Surface Roughness Parameters. In: Keyence [Internet]. Available: https://www.keyence.com/ss/products/microscope/ roughness/surface/parameters.jsp. Accesed 22 Mar 2021

81. Shamvedi D, McCarthy OJ, Donoghue EO, Leary PO, Raghavendra $\mathrm{R}$ (2017) 3D metal printed monocone antenna with an integrated feed. 2017 47th European microwave conference (EuMC). ieeexplore.ieee.org; pp. 168-171

82. Puente-Baliarda C, Romeu J, Pous R, Cardama A (1998) On the behavior of the Sierpinski multiband fractal antenna. IEEE Trans Antennas Propag 46:517-524

83. Stutzman WL, Thiele GA (2012) Antenna theory and design. Wiley, Hoboken

84. Saeed AR, Khatun S (2004) Design of microstrip antenna for WLAN. J Appl Sci 5:47-51 